(2) Open Access Full Text Article

\title{
An exploratory study evaluating the effects of macular carotenoid supplementation in various retinal diseases
}

This article was published in the following Dove Press journal:

Clinical Ophthalmology

II May 2016

Number of times this article has been viewed

\section{Roxanne Crosby-Nwaobi \\ Philip Hykin \\ Tunde Peto \\ Sobha Sivaprasad}

NIHR Clinical Research Facility, NIHR Moorfields Biomedical Research Centre, London, UK
Correspondence: Sobha Sivaprasad NIHR Moorfields Biomedical Research Centre, 162 City Road, ECIV 2PD London, UK

Tel +442032994548

Fax +442032993738

Email senswathi@aol.com
Purpose: The aim of this study was to assess the impact of daily oral supplementation with Macushield (10 mg/d meso-zeaxanthin, $10 \mathrm{mg} / \mathrm{d}$ lutein, and $2 \mathrm{mg} / \mathrm{d}$ zeaxanthin) on eye health in patients with retinal diseases by assessing the macular pigment (MP) profile, the visual function, and the quality of life.

Methods: Fifty-one patients with various retinal diseases were supplemented daily and followed up for 6 months. The MP optical density was measured using the customized heterochromatic flicker photometry and dual-wavelength autofluorescence. Visual function was evaluated by assessing the change in best corrected visual acuity, contrast sensitivity, and glare sensitivity in mesopic and photopic conditions. Vision-related and general quality of life changes were determined using the National Eye Insititute- Visual Function Questionnaire-25 (NEI-VFQ-25) and EuroQoL-5 dimension questionnaires.

Results: A statistically significant increase in the MP optical density was observed using the dual-wavelength autofluorescence $(P=0.04)$ but not with the customized heterochromatic flicker photometry. Statistically significant $(P<0.05)$ improvements in glare sensitivity in low and medium spatial frequencies were observed at 3 months and 6 months. Ceiling effects confounded other visual function tests and quality of life changes.

Conclusion: Supplementation with the three carotenoids enhances certain aspects of visual performance in retinal diseases.

Keywords: macular pigment optical density, diabetes, central serous retinopathy, age-related macular degeneration

\section{Introduction}

The past decade has witnessed an increasing interest in the possible beneficial role of macular pigment (MP) in aspects of visual performance. ${ }^{1}$ The MP composed of xanthophyll carotenoids, lutein, zeaxanthin, and meso-zeaxanthin is concentrated within the photoreceptor axons of the foveola and the plexiform layers of the macula. ${ }^{2}$ The prereceptoral location and short-wavelength absorption by MP may together limit photooxidative damage to retinal cells and maintain the quality of vision. ${ }^{3}$

Oxidative stress contributes to the pathogenesis of several retinal diseases, such as age-related maculopathy (ARM) and diabetic retinopathy (DR). ${ }^{4,5}$ The role of oxidants in more acute conditions remains unclear.

Generally, retinal diseases that affect the macula result in poor central visual performance. Some macular disorders are amenable to treatment, but efficacy may be limited, highlighting the importance of optimizing the visual performance and minimizing the factors that may exacerbate the progression. 
Lutein and zeaxanthin are of dietary origin, whereas mesozeaxanthin is not typically found in diet but has been identified in some fish species. ${ }^{6,7}$ Interestingly, however, the concentrations of lutein, zeaxanthin, and meso-zeaxanthin at the macula are in equal amounts (in a ratio of $1: 1: 1),{ }^{8}$ and meso-zeaxanthin is believed to be formed at the macula by conversion from lutein, ${ }^{9}$ but the mechanism for such a conversation has not yet been confirmed, and further work in this area is merited. ${ }^{10}$ A substantial proportion of patients in the Lutein Nutrition effects measured by Autofluorescence (LUNA) study and in the Carotenoids in Age-related Eye Disease Study (CAREDS) showed no change in MP optical density (MPOD) following supplementation with lutein and zeaxanthin. ${ }^{11,12}$ The retinal uptake of circulating carotenoids is likely influenced by an individual's genetic make-up, lipoprotein and apolipoprotein profiles, body fat content, and local ocular factors that include the degradation properties of local oxidants. ${ }^{12}$ The complexity of such interactions may explain the contradictions and controversies in the literature relating to the effects of carotenoid supplementation. It is also possible that changes in MP levels in the retina may be under- or overestimated by the measurement method; ${ }^{13,14}$ some methods have focused on the peak MPOD at the fovea relative to an eccentric retinal location and have ignored the majority of the total pigment complement, located over paracentral macular locations. ${ }^{14,15}$

In this exploratory study, we aim to evaluate the effect of oral MP supplementation in eyes with retinal pathology in terms of peak MPOD, total complement of MP, and visual performance.

\section{Methods}

\section{Ethics statement}

This interventional, prospective, exploratory study (EudraCT number 2013-005286-39) was conducted following the approval from the Institutional Review Board Ethics Committee (12/LO/1139) (NRES Committee London City and East London), and all participants gave their written informed consent. The study adhered to the principles of the Declaration of Helsinki.

\section{Patients}

The key inclusion criteria were patients of either sex aged 18 years or older attending the Medical Retina Clinics for any retinal problem with adequate media clarity, pupillary dilation, and subject cooperation sufficient for visual function tests and retinal imaging. Patients with previous macular laser, pan retinal photocoagulation, glaucoma, or decreased vision due to nonretinal causes were excluded.
Patients who attended all the Medical Retina Clinics in Moorfields Eye Hospital and who were eligible for this study based on the inclusion/exclusion criteria were invited to participate in the study, and a patient information sheet was provided. Informed consent was obtained from the patients prior to performing any study procedure. All eyes continued to receive usual clinical care appropriate for the management of the retinal disease. We included 51 patients in this study, and 49 patients completed the study.

\section{Intervention}

MP supplementation consisting of $10 \mathrm{mg}$ lutein, $2 \mathrm{mg}$ zeaxanthin, and $10 \mathrm{mg}$ meso-zeaxanthin was provided as commercially available food supplement; Macushield capsules were supplied by Macuvision Europe (West Midlands, UK), which is now a part of Alliance Pharma Plc. The Macushield capsules were taken orally once daily for 6 months. The hospital pharmacy was responsible for drug accountability. All unused Macushield capsules were returned to the trial (EudraCT number 2013-005286-39) pharmacist who maintained the drug accountability log in the hospital pharmacy file.

\section{Assessments}

After receiving the written informed consent at screening, patients underwent MP measurements, visual function tests, ocular examination, retinal imaging, and answered the questionnaires.

\section{Assessment of MP}

The MPOD was measured using the following two techniques: customized heterochromatic flicker photometry (cHFP) and dual-wavelength autofluorescence (DWAF). Using cHFP, MPOD was measured using a $1^{\circ}$ circular stimulus centered on the fovea. The stimulus field flickered between $458 \mathrm{~nm}$ (close to peak MP absorbance) and $570 \mathrm{~nm}$ (outside the MP absorption spectrum), and the radiance of one component was adjusted to achieve a subject-specific flicker null. A similar measurement was obtained using a $4^{\circ}$ circular field centered at $7^{\circ}$ eccentricity. MPOD was computed from the radiance settings at the central location relative to those at the eccentric location. Patients had a practice session prior to test commencement. cHFP flicker frequencies were optimized following the determination of individual critical flicker fusion frequency measurements; this aimed to maximize the ease and accuracy of cHFP measurements. Each flicker null was measured on four occasions, and the average reading at each retinal location was used to compute a mean MPOD value relative to that at $7^{\circ}$ 
eccentricity. For the purposes of this study, it was assumed that the relative MPOD value obtained for the central area was equivalent to the value at the edge of the circular stimulus, ie, at $0.5^{\circ}$ eccentricity. ${ }^{16-18}$ Patients underwent DWAF imaging using a modified confocal scanning laser ophthalmoscope (Heidelberg HRA, Heidelberg, Germany). Images were obtained using two argon lasers (radiation $488 \mathrm{~nm}$ and $514 \mathrm{~nm}$ ) and aligned automatically according to the anatomic landmarks, such as the retinal blood vessels. A map of the relative MPOD of each pixel was obtained by digital subtraction of the log autofluorescence data at the two wavelengths. The MPOD maps were used to compute the mean two-dimensional distribution profiles in each patient relative to the mean value for an annulus at $7^{\circ}$ (comparable to the cHFP method) and $10.5^{\circ}$ eccentricities. MPOD with reference to $7^{\circ}$ and the total complement of MP (analogous to volume) were obtained for the central $21^{\circ}$ by summating pixel-related optical density values. For direct comparison with the cHFP technique, the MPOD value at $0.5^{\circ}$ eccentricity was measured.

\section{Visual function tests}

All visual function tests were performed at baseline and repeated at 3 months and 6 months. These tests included best corrected visual acuity (BCVA), contrast sensitivity, mesopic and photopic contrast sensitivities with and without glare sensitivity, and vision-related quality of life questionnaire (NEI-VFQ-25). ${ }^{41}$

BCVA for each eye was measured using the standard Early Treatment of Diabetic Retinopathy Study (ETDRS) protocol at $4 \mathrm{~m}$ distance with a modified ETDRS distance chart. Visual acuity was scored as the total number of ETDRS letters read correctly at $1 \mathrm{~m}$.

Contrast sensitivity measurement was performed after visual acuity measurements, with the Pelli-Robson chart (Clement Clarke Inc., Harlow, UK) at a distance of $1 \mathrm{~m}$ and chart luminance of $80-120 \mathrm{~cd} / \mathrm{m}^{2}$.

Contrast sensitivity function in varying day-to-day conditions including glare sensitivity was also measured using the functional acuity contrast test (FACT; Functional Vision Analyzer $^{\circledR}$; Stereo Optical, Chicago, IL, USA). This unit allows the background illumination within the unit to be monitored and controlled, so that photopic and mesopic contrast and glare sensitivity can be measured at different levels. The contrast sensitivity function was measured at spatial frequencies of $1.5 \mathrm{cpd}, 3 \mathrm{cpd}, 6 \mathrm{cpd}, 12 \mathrm{cpd}$, and $18 \mathrm{cpd} .{ }^{19}$

The NEI-VFQ-25 has been developed by the National Eye Institute. ${ }^{20}$ This validated self-administered questionnaire consists of 25 questions, with a total score and subscores ranging from 0 to 100 . In this questionnaire, the score of 0 corresponds to the lowest vision-related quality of life and the score of 100 corresponds to the highest vision-related quality of life. There are twelve subscales, each consisting of one or more questions. These subscales are general health, general vision, ocular pain, near activities, distance activities, vision-specific social functioning, vision-specific mental health, vision-specific role difficulties, vision-specific dependency, driving, color vision, and peripheral vision.

The EuroQoL-5 dimension (EQ-5D) is a validated, generalized, and standardized instrument measuring self-rated general health-related quality of life, consisting of a threelevel response (no problems, some problems, and extreme problems) for the following five domains related to daily activities; 1) mobility, 2) self-care, 3) usual activities, 4) pain and discomfort, and 5) anxiety and depression. ${ }^{21}$

\section{Retinal imaging}

The macular thickness and morphology was assessed using the Spectralis spectral domain optical coherence tomography (OCT). The OCT volume scan was performed at every visit on a $20^{\circ} \times 20^{\circ}$ cube, with 49 horizontal raster lines, each containing 1,064 pixels, separated by $125 \mu \mathrm{m}$. Two-field fundus color photographs were performed at baseline and exit visit at 6 months.

\section{Food frequency questionnaire}

Each patient was questioned as to their weekly intake of carotenoid-rich foods at baseline, 3 months, and 6 months. Carotenoid-rich foods were defined as dark leafy vegetables, broccoli, eggs, and corn. The carotenoid diet score of the patient was obtained after imputing the patient's answers into the lutein/zeaxanthin screener. This screener has been previously described by Nolan et al. ${ }^{22}$ Low, medium, and high carotenoid dietary intake was defined as score $0-15$ ( $\leq 2 \mathrm{mg} / \mathrm{d})$, score $16-30(2<x \leq 13 \mathrm{mg} / \mathrm{d})$, and score $31-75$ $(>13 \mathrm{mg} / \mathrm{d})$, respectively.

\section{Assessment of compliance}

Patient compliance with study drug was assessed at each visit. Compliance was monitored by capsule counts performed by site pharmacy personnel at 3 months and 6 months. Compliance was evaluated as the percentage of prescribed pills taken since the previous evaluation. If this percentage is $\leq 80$ for the time period, then the patient was categorized as noncompliant for the time period since previous evaluation. Noncompliance was not a reason for termination from the 
study, but the reasons for noncompliance were explored and documented. Site personnel took extra efforts to ensure that noncompliant patients improve their compliance by frequent telephone reminders and counseling. Any deviations from the prescribed dosage regimen were recorded.

\section{Outcome measures}

The primary outcome measure was the median change in peak MPOD at 6 months. The secondary outcomes included changes in MPOD at 3 months, mean change in "total" MP at 3 months and 6 months, mean change in BCVA in ETDRS letters, contrast sensitivity using the Pelli-Robson chart, photopic and mesopic contrast sensitivity with and without glare sensitivity measured using the FACT, NEI-VFQ-25, and EQ-5D scores over 6 months.

The anatomical changes measured included change in central subfield thickness on OCT over 6 months. The changes in diet assessed by the food frequency questionnaire and compliance to treatment were also evaluated.

All changes in glycated hemoglobin in people with diabetes were recorded. Adverse events were collected and reported.

\section{Statistics}

Descriptive data summaries (mean, SD, median, and range) were calculated at 3 months and 6 months. The primary efficacy analysis of the change from baseline in MPOD using the Heterochromic Flicker Frequency (HFF) and DWAF and total MP using the DWAF was analyzed using ANCOVA. All the secondary outcome measures were analyzed regardless of the significance of the primary outcome measure. Differences between two time points within patients were assessed using the paired-samples $t$-tests for parametric data or Wilcoxon rank sum test for nonparametric data. Statistical significance was set at the 5\% level, and all analyses were undertaken using IBM SPSS Statistics Version 21 (IBM Corporation, Armonk, NY, USA). As the trial is exploratory, no formal power calculation was done.

\section{Results}

\section{Baseline characteristics}

Sixty-seven patients were approached in clinics, and 51 patients agreed to participate in this study. Of the 51 patients recruited, 49 patients completed the study with two withdrawals after visit 1 . Therefore, we report data for $\mathrm{n}=49$ patients (Table 1 ). The first patient was recruited on December 5, 2012, and the last patient exited the study on January 14, 2014. The two patients who withdrew from the study voluntarily discontinued, and withdrawal for both
Table I Baseline demographics of the study participants

\begin{tabular}{|c|c|}
\hline Variables & Data \\
\hline Number of patients (eyes), $n$ & $49(49)$ \\
\hline \multicolumn{2}{|l|}{ Sex, n (\%) } \\
\hline Males & $23(46.9)$ \\
\hline Females & $26(53.1)$ \\
\hline Age (years), mean (SD) & $59.4 \pm 13.6$ \\
\hline \multicolumn{2}{|l|}{ Ethnicity, n (\%) } \\
\hline Asian or Asian British & $12(24.5)$ \\
\hline Black or Black British & $3(6.1)$ \\
\hline White or White British & $34(69.4)$ \\
\hline Diabetes, n (\%) & $26(53.1)$ \\
\hline Type I & $3(I 1.5)$ \\
\hline Type 2 & $23(88.5)$ \\
\hline BMI $\left(\mathrm{kg} / \mathrm{m}^{2}\right)$, mean $(\mathrm{SD})$ & $28.8 \pm 6.1$ \\
\hline $\mathrm{HbAlc}(\%)$, mean (SD) in diabetic population & $8.3 \pm 1.9$ \\
\hline Systolic BP (mmHg), mean (SD) & $134.9 \pm 17.3$ \\
\hline Diastolic BP (mmHg), mean (SD) & $83 \pm 13.2$ \\
\hline \multicolumn{2}{|l|}{ Retinal diseases, N (\%) } \\
\hline Normal & $4(8.2)$ \\
\hline \multicolumn{2}{|l|}{ Diabetic retinopathy } \\
\hline DR with no macular edema & $10(20.4)$ \\
\hline DR with macular edema & $10(20.4)$ \\
\hline Early ARM & $12(24.5)$ \\
\hline AMD & $8(16.3)$ \\
\hline CSR & $5(10.2)$ \\
\hline BCVA (ETDRS letters), mean (SD) & $83.2 \pm 7.6$ \\
\hline
\end{tabular}

Abbreviations: AMD, age-related macular degeneration; ARM, age-related maculopathy; BCVA, best corrected visual acuity; BMI, body mass index; BP, blood pressure; CSR, central serous retinopathy; DR, diabetic retinopathy; ETDRS, Early Treatment of Diabetic Retinopathy Study; HbAIc, glycated hemoglobin.

patients was assigned as not supplement related. Over half of the patients had diabetes. One eye was allocated as the study eye for this project. The study eyes had the following characteristics: normal eyes $(n=4)$, DR with no macular edema $(n=10)$, diabetic macular edema $(n=10)$, age-related macular degeneration (AMD; early ARM, $n=12$; advanced AMD, $n=8)$, and central serous retinopathy $(C S R, n=5)$.

\section{Customized heterochromatic flicker photometry MPOD}

The mean MPOD \pm SD values were $0.49 \pm 0.04$ at baseline, $0.54 \pm 0.05$ at 3 months, and $0.52 \pm 0.07$ at 6 months. The frequency of distribution of cHFP MPOD values of the 49 patients over the period of the study is shown in Table 2 with more patients progressing to above the baseline MPOD with oral supplementation. However, the results were not statistically significant.

\section{Dual-wavelength autofluorescence}

We found an increase in mean DWAF MPOD at 3 months and a statistically significant increase at 6 months with reference to $7^{\circ}(P=0.31$ and $P=0.041$, respectively; Table 2$)$. 
Table 2 Change in macular pigment optical density and total macular pigment complement using the DWAF

\begin{tabular}{|c|c|c|c|c|c|c|c|}
\hline Parameter & $\begin{array}{l}\text { Baseline, } \\
\text { mean (SD) }\end{array}$ & $\begin{array}{l}3 \text { months } \\
\text { mean (SD) }\end{array}$ & $\begin{array}{l}\text { Change in } \\
0-3 \text { months, } \\
\text { mean (SD) }\end{array}$ & $P$-value & $\begin{array}{l}6 \text { months, } \\
\text { mean (SD) }\end{array}$ & $\begin{array}{l}\text { Change in } \\
0-6 \text { months, } \\
\text { mean (SD) }\end{array}$ & $P$-value \\
\hline \multicolumn{8}{|c|}{ Macular pigment optical density: $n=49$} \\
\hline $\begin{array}{l}\text { DWAF optical density } 0.5 \\
\text { with } 7^{\circ} \text { reference }\end{array}$ & $0.3 I \pm 0.25$ & $0.39 \pm 0.26$ & $0.08 I \pm 0.26$ & 0.31 & $0.39 \pm 0.27$ & $0.082 \pm 0.274$ & 0.041 \\
\hline \multicolumn{8}{|c|}{ Macular pigment volume: $n=49$} \\
\hline $\begin{array}{l}\text { DWAF volume with } 10.5^{\circ} \\
\text { reference }\end{array}$ & $3,466.7 \pm 3,179.3$ & $5,048.5 \pm 3,376.6$ & $1,581.8 \pm 3,627.1$ & 0.004 & $5,791.1 \pm 4, I 10.0$ & $2,324.3 \pm 4,134.1$ & $<0.001$ \\
\hline
\end{tabular}

Notes: Results are in response to an analysis of variance; significant $P$-values are those $<0.05$.

Abbreviation: DWAF, dual-wavelength autofluorescence.

The percentage change in the total complement of MP within the central $21^{\circ}$ was $45.5 \%$ at 3 months and $67.0 \%$ at 6 months.

\section{MP spatial profile using DWAF in various disease groups}

The macular spatial profiles of MPOD averaged for different disease groups are compared in Figure 1. Normal eyes showed a mean relative MPOD of $0.71 \pm 0.21$ at $0.5^{\circ}$ eccentricity. There was a significant overlap in profile between diseases and with normal eyes. Figure 1 shows the mean baseline MPOD in each disease group. Individuals with CSR had the lowest mean MPOD at $0.5^{\circ}$ eccentricity $(0.44 \pm 0.21)$. The mean MPOD was $0.52 \pm 0.35$ in eyes with mild DR with dry macula, $0.64 \pm 0.32$ in eyes with DR with maculopathy, and $0.60 \pm 0.32$ in eyes with early age-related macular changes, including drusen and retinal pigment epithelial changes, and $0.52 \pm 0.20$ in eyes with advanced macular degeneration. Following the supplementation, there was a significant increase in the measurements of total MP complement (Figure 2), which was greatest for eyes with CSR and diabetic maculopathy.

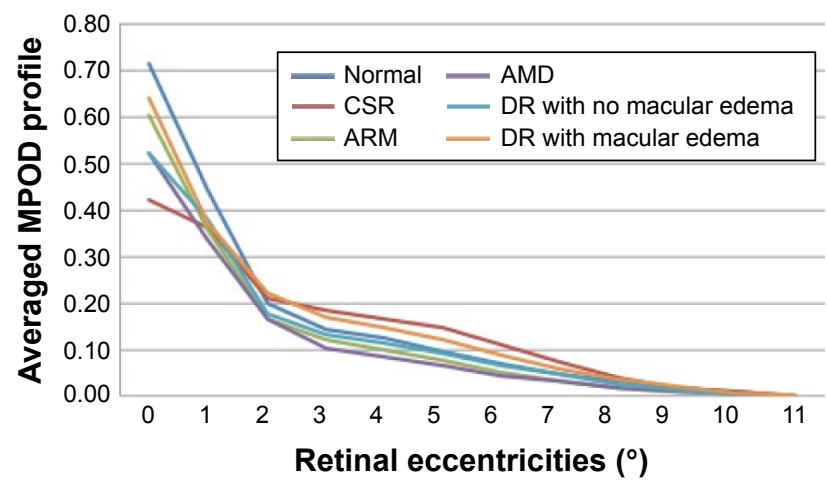

Figure I Averaged MPOD profiles in patients at baseline per retinal disease. Abbreviations: AMD, age-related macular degeneration; ARM, age-related maculopathy; CSR, central serous retinopathy; DR, diabetic retinopathy; MPOD, macular pigment optical density.

\section{Visual performance}

The mean \pm SD BCVAs at baseline, 3 months, and 6 months were $83.2 \pm 7.6,82.7 \pm 9.1$, and $84.4 \pm 8.2$, respectively. There was no statistical difference in BCVA from baseline to 3 months $(P=0.807)$. However, there was a significant improvement in BCVA from baseline to 6 months $(P=0.038)$.

The mean Pelli-Robson contrast sensitivity score was also found to be not significant between baseline (36.1 \pm 4.2$)$ and 3 months (36.6 \pm 4.7$)$ and 6 months $(37.3 \pm 4.2 ; P=0.531$ and $P=0.821$, respectively). At 6 months, the change in contrast sensitivity ranged from -6 to +10 letters.

The FACT showed that contrast sensitivity improved from baseline for several spatial frequencies at 3 months and 6 months in both photopic and mesopic conditions (Table 3). Contrast sensitivity under glare conditions also showed a statistically significant improvement from baseline for several spatial frequencies at 3 months and 6 months in both photopic and mesopic conditions.

\section{NEI-VFQ-25 by total and subscales}

There was a significant improvement in the vision-related quality of life from baseline to 3 months and baseline to

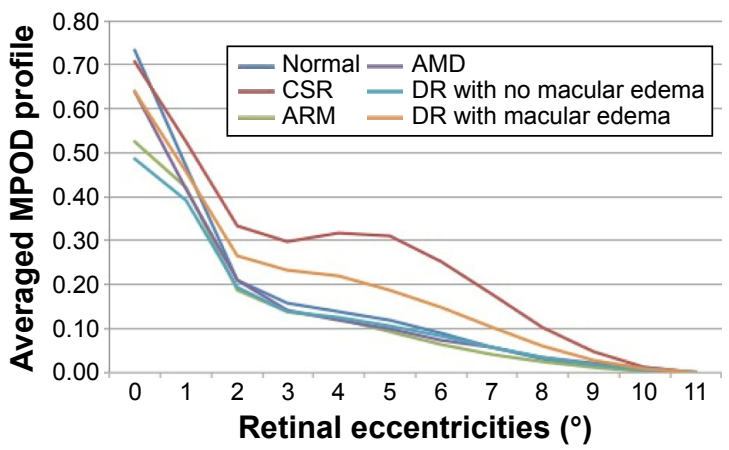

Figure 2 Averaged MPOD profiles in patients at 6 months post-supplementation per retinal disease.

Abbreviations: AMD, age-related macular degeneration; ARM, age-related maculopathy; CSR, central serous retinopathy; DR, diabetic retinopathy; MPOD, macular pigment optical density. 
Table 3 Change in contrast sensitivity measurements in various conditions

\begin{tabular}{|c|c|c|c|c|c|c|c|}
\hline $\begin{array}{l}\text { Spatial } \\
\text { frequency } \\
\text { (cycles) }\end{array}$ & $\begin{array}{l}\text { Baseline, } \\
\text { mean (SD) }\end{array}$ & $\begin{array}{l}3 \text { months, } \\
\text { mean (SD) }\end{array}$ & $\begin{array}{l}\text { Change in } \\
0-3 \text { months, } \\
\text { mean (SD) }\end{array}$ & $P$-value & $\begin{array}{l}6 \text { months, } \\
\text { mean (SD) }\end{array}$ & $\begin{array}{l}\text { Change in } \\
0-6 \text { months, } \\
\text { mean (SD) }\end{array}$ & $P$-value \\
\hline \multicolumn{8}{|c|}{ Night testing with glare } \\
\hline 1.5 & $18.6 \pm 19.4$ & $33.3 \pm 27.9$ & $14.7 \pm 26.5$ & 0.001 & $37.5 \pm 25.7$ & $18.9 \pm 23.7$ & $<0.00$ \\
\hline 3 & $33.2 \pm 25.8$ & $56.3 \pm 34.9$ & $23.2 \pm 36.5$ & 0.002 & $58.9 \pm 39.0$ & $25.7 \pm 36.1$ & 0.001 \\
\hline 6 & $25.3 \pm 18.9$ & $55.5 \pm 52.4$ & $30.2 \pm 46.0$ & 0.003 & $48.5 \pm 40.7$ & $24.3 \pm 36.3$ & 0.002 \\
\hline 12 & $7.1 \pm 4.3$ & $15.9 \pm 17.8$ & $8.8 \pm 16.7$ & 0.053 & $17.2 \pm 15.6$ & $9.8 \pm 15.9$ & 0.047 \\
\hline 18 & $2.8 \pm 1.1$ & $4.0 \pm 4.5$ & $1.2 \pm 3.9$ & 0.529 & $3.2 \pm 2.7$ & $0.4 \pm 1.6$ & 1.00 \\
\hline \multicolumn{8}{|c|}{ Night testing without glare } \\
\hline $1.5^{\circ}$ & $40.4 \pm 31.2$ & $56.6 \pm 33.0$ & $16.2 \pm 27.9$ & $<0.001$ & $65.2 \pm 30.6$ & $24.7 \pm 31.7$ & $<0.001$ \\
\hline 3 & $47.7 \pm 32.0$ & $74.8 \pm 45.8$ & $27.1 \pm 37.2$ & $<0.001$ & $81.3 \pm 45.6$ & $33.6 \pm 48.6$ & $<0.00$ I \\
\hline 6 & $39.2 \pm 33.2$ & $59.6 \pm 44.5$ & $20.4 \pm 31.2$ & $<0.001$ & $74.3 \pm 59.0$ & $34.6 \pm 48.6$ & $<0.001$ \\
\hline 12 & $9.2 \pm 7.3$ & $19.8 \pm 20.7$ & $10.6 \pm 17.3$ & 0.004 & $23.9 \pm 26.7$ & $15.0 \pm 23.0$ & 0.002 \\
\hline 18 & $3.8 \pm 3.6$ & $7.1 \pm 5.3$ & $3.4 \pm 5.1$ & 0.103 & $9.3 \pm 6.9$ & $4.7 \pm 6.5$ & 0.065 \\
\hline \multicolumn{8}{|c|}{ Day testing with glare } \\
\hline 1.5 & $36.9 \pm 25.9$ & $52.4 \pm 30.5$ & $15.5 \pm 24.8$ & $<0.001$ & $51.7 \pm 28.7$ & $14.8 \pm 29.5$ & 0.002 \\
\hline 3 & $56.6 \pm 34.8$ & $84 . I \pm 4 I .1$ & $27.5 \pm 35.7$ & $<0.001$ & $83.3 \pm 42.8$ & $28.5 \pm 41.8$ & $<0.001$ \\
\hline 6 & $56.6 \pm 34.8$ & $81.4 \pm 51.6$ & $24.7 \pm 43.3$ & 0.001 & $88.4 \pm 58.1$ & $32.5 \pm 51.3$ & $<0.001$ \\
\hline 12 & $26.0 \pm 22.5$ & $33.0 \pm 27.0$ & $7.0 \pm 20.1$ & 0.05 & $39.6 \pm 35.1$ & $14.9 \pm 30.4$ & 0.008 \\
\hline 18 & $10.3 \pm 7.2$ & $15.4 \pm 17.2$ & $5.0 \pm 13.1$ & 0.078 & $14.3 \pm 13.1$ & $4.5 \pm 10.2$ & 0.036 \\
\hline \multicolumn{8}{|c|}{ Day testing without glare } \\
\hline 1.5 & $36.7 \pm 24.6$ & $52.0 \pm 28.2$ & $15.2 \pm 24.8$ & $<0.001$ & $57.0 \pm 31.3$ & $20.1 \pm 30.9$ & $<0.001$ \\
\hline 3 & $53.6 \pm 31.8$ & $77.6 \pm 2.85$ & $24.0 \pm 33.8$ & $<0.001$ & $85.9 \pm 49.4$ & $32.2 \pm 44.5$ & $<0.001$ \\
\hline 6 & $62.9 \pm 49.8$ & $86.3 \pm 55.3$ & $23.4 \pm 35.7$ & $<0.001$ & $90.3 \pm 59.4$ & $27.1 \pm 44.5$ & $<0.001$ \\
\hline 12 & $27.8 \pm 23.1$ & $42.7 \pm 35.4$ & $14.9 \pm 22.2$ & 0.001 & $53.0 \pm 42.7$ & $25.9 \pm 34.5$ & $<0.001$ \\
\hline 18 & $8.9 \pm 7.7$ & $13.0 \pm 14.4$ & $4.1 \pm 11.3$ & $0.07 I$ & $|4.0 \pm| \mid .3$ & $4.9 \pm 10.4$ & 0.022 \\
\hline
\end{tabular}

6 months ( $P=0.005$ and $P=0.002$, respectively). Statistically significant changes were also found in the subscales of NEI-VFQ-25 (Table 4). At 3 months, patients reported an improvement in distance activities $(P=0.028)$, mental health $(P=0.006)$, and peripheral vision $(P=0.048)$. At 6 months, patients reported an improvement in near activities $(P=0.001)$, distance activities $(P=0.017)$, mental health $(P=0.003)$, and role difficulties $(P=0.043)$. There was a ceiling effect for the EQ-5D utility score (77\%). Serious ceiling effects existed in all domains of EQ-5D, and the largest ceiling effect was observed for mobility (82\%) and self-care (92\%) domains. No patient scored at the floor of the EQ-5D utility. Three participants who showed an improvement in anxiety and depression drove the EQ-5D results. Serious ceiling effects existed in all domains of NEI-VFQ-25, and $57.1 \%$ of patients scored $\geq 87.5$ at baseline. No patient scored at the floor of the NEI-VFQ-25 domain scores.

\section{Optical coherence tomography}

There is no significant change in central retinal subfield thickness between the study visits in the total study population: 3 months, $P=0.708 ; 6$ months, $P=0.613$. Analyses for change in central subfield thickness also revealed no significant change in central retinal subfield thickness $(P>0.05)$.

\section{Compliance to supplementation}

Mean \pm SD supplement compliance for the study at 6 months was $99.3 \% \pm 3.3 \%$. There was no reported change to the carotenoid content of the participant's diet based on the completed food frequency questionnaire.

\section{Safety outcomes}

There were 16 adverse events and none were related to the supplementation. We attributed the indigestion reported by the participant who withdrew to a past medical history of acid peptic disease. In most patients $(78.3 \%)$, there was either no change or a decrease in glycated hemoglobin at 3 months compared to baseline (range: 0.0 to -2.7 ). This proportion increased slightly to $80 \%$ at 6 months compared to baseline (range: 0.0 to -3.5$)$. Only one patient $(2 \%)$ required treatment as per the standard of care during the period of the study.

\section{Discussion}

This exploratory study shows that oral supplementation with a combination of lutein $10 \mathrm{mg}$, zeaxanthin $2 \mathrm{mg}$, and 
Table 4 Change in the quality of life as measured by NEI-VFQ-2520 and EQ-5D ${ }^{39}$

\begin{tabular}{|c|c|c|c|c|c|c|c|}
\hline Parameters & $\begin{array}{l}\text { Baseline, } \\
\text { mean (SD) }\end{array}$ & $\begin{array}{l}3 \text { months, } \\
\text { mean (SD) }\end{array}$ & $\begin{array}{l}\text { Change in } \\
0-3 \text { months, } \\
\text { mean (SD) }\end{array}$ & $P$-value & $\begin{array}{l}6 \text { months, } \\
\text { mean (SD) }\end{array}$ & $\begin{array}{l}\text { Change in } \\
0-6 \text { months, } \\
\text { mean (SD) }\end{array}$ & $P$-value \\
\hline \multicolumn{8}{|c|}{ Vision-related quality of life } \\
\hline NEI-VFQ-25 composite & $84.8 \pm \mid 4.5$ & $87.8 \pm 11.9$ & $3.04 \pm 6.98$ & 0.005 & $89.3 \pm 11.5$ & $3.58 \pm 7.11$ & 0.002 \\
\hline Effect size & & & & 0.23 & & & 0.34 \\
\hline \multicolumn{8}{|l|}{ Subscales } \\
\hline General health & $62.2 \pm 23.6$ & $60.6 \pm 19.6$ & $-1.7 \pm 17.8$ & 0.538 & $58.9 \pm 19.3$ & $-3.3 \pm 17.4$ & 0.204 \\
\hline General vision & $70.2 \pm 19.4$ & $74.2 \pm 17.9$ & $4.0 \pm 13.9$ & 0.060 & $76.0 \pm 15.7$ & $3.1 \pm 14.7$ & 0.164 \\
\hline Ocular pain & $84.2 \pm 16.1$ & $86.4 \pm 16.0$ & $2.2 \pm 14.7$ & 0.315 & $87.8 \pm 14.0$ & $3.6 \pm 13.5$ & 0.079 \\
\hline Near activities & $80.6 \pm 21.5$ & $83.1 \pm 19.0$ & $2.3 \pm 11.9$ & 0.151 & $87.5 \pm 18.9$ & $5.6 \pm 10.3$ & 0.001 \\
\hline Effect size & & & & & & & 0.34 \\
\hline Distance activities & $85.3 \pm 18.2$ & $88.2 \pm 16.1$ & $3.0 \pm 8.7$ & 0.028 & $89.0 \pm 16.9$ & $3.7 \pm 10.0$ & 0.017 \\
\hline Effect size & & & & 0.17 & & & 0.28 \\
\hline Social functioning & $93.3 \pm 915.2$ & $95.3 \pm 11.7$ & $1.9 \pm 8.4$ & 0.128 & $95.6 \pm 11.0$ & $1.9 \pm 7.5$ & 0.090 \\
\hline Mental health & $80.0 \pm 21.3$ & $86.3 \pm 12.5$ & $6.3 \pm 14.7$ & 0.006 & $87.1 \pm 14.8$ & $5.3 \pm 11.5$ & 0.003 \\
\hline Effect size & & & & 0.36 & & & 0.39 \\
\hline Role difficulties & $80.3 \pm 22.4$ & $84.2 \pm 20.5$ & $3.9 \pm 19.7$ & 0.193 & $86.7 \pm 19.1$ & $5.3 \pm 17.0$ & 0.043 \\
\hline Dependency & $94.6 \pm 15.0$ & $95.2 \pm 11.0$ & $0.6 \pm 10.7$ & 0.730 & $95.9 \pm 10.1$ & $0.6 \pm 9.6$ & 0.701 \\
\hline Driving & $90.3 \pm 17.0$ & $92.7 \pm 16.0$ & $2.3 \pm 8.2$ & 0.166 & $93.0 \pm 16.3$ & $3.3 \pm 9.0$ & 0.076 \\
\hline Color vision & $93.3 \pm 16.3$ & $95.0 \pm 12.6$ & $1.7 \pm 15.4$ & 0.473 & $97.2 \pm 9.6$ & $2.2 \pm 14.9$ & 0.323 \\
\hline Peripheral vision & $85.6 \pm 23.5$ & $90.6 \pm 16.2$ & $5.0 \pm 16.5$ & 0.048 & $90.6 \pm 16.2$ & $5.0 \pm 18.2$ & $0.07 I$ \\
\hline Effect size & & & & 0.25 & & & \\
\hline \multicolumn{8}{|c|}{ Quality of life - overall health score index } \\
\hline EQ-5D & $0.89 \pm 0.13$ & $0.89 \pm 0.13$ & $0.005 \pm 0.083$ & 0.706 & $0.92 \pm 0.13$ & $0.032 \pm 0.096$ & 0.034 \\
\hline Effect size & & & & & & & 0.23 \\
\hline
\end{tabular}

Notes: Results are in response to an analysis of variance; significant $P$-values are those $<0.05$.

Abbreviation: EQ-5D, EuroQoL-5 dimension.

meso-zeaxanthin $10 \mathrm{mg}$ daily for 6 months in patients with retinal pathology increased the mean MPOD and mean total complement of MP at 6 months when measured using the DWAF. These changes were associated with significant increases in contrast sensitivity at low and medium spatial frequencies. Other visual function tests and quality of life changes also showed improvements.

The significant changes in MPOD parameters revealed using the objective DWAF measurement technique were not detected using cHFP. The reasons for this discrepancy may be both measurement and disease related. Previous studies have demonstrated high correlation and correspondence between the DWAF and minimum flicker ${ }^{23}$ and minimum motion $^{24}$ techniques. However, psychophysical measurements are subjective and may be difficult for naïve observers, particularly in the context of retinal disease associated with an impaired visual function, and this was consistent with the large intrasession SDs for cHFP in some patients. Canovas et al assessed the reliability and validity of cHFP as a measurement tool for MPOD. They recommended that cHFP was suitable for use in patients with no retinal pathology as the unreliability of data increased in the presence of retinal pathology and increased age. ${ }^{23}$ The discrepancy may also relate to methodology; the cHFP instrument used in this study involved a computation of MPOD relative to the value obtained for a $4^{\circ}$ field centered at $7^{\circ}$ eccentricity (between $5^{\circ}$ and $9^{\circ}$ eccentricity), but the MPOD may vary significantly over these eccentricities (Figure 1). Additionally, localized retinal pathology may affect the reference and central locations differently; such effects would be less using the DWAF as measurements are derived from radial measurements (concentric circles).

There is a growing body of evidence showing that oral supplementation of the three carotenoids improves mean MPOD. ${ }^{1,24-26}$ However, our study shows significant interindividual variations in "central" MPOD. This may be related to the primary condition of the retina. There is evidence from studies on patients with chronic CSR and advanced AMD that the uptake of oral carotenoids by degenerated retina is unpredictable. ${ }^{27,28}$ Multiple factors such as saturation of carotenoid-binding proteins ${ }^{29}$ and reduced load of health retinal cells that can perform the function ${ }^{30}$ may explain these variations.

Oral supplementation of these carotenoids improved the mesopic and photopic contrast sensitivities and glare sensitivity in people with retinal diseases. Patients with 
retinal diseases have problems seeing in dim lighting and at night despite minimal or no impairment in visual acuity measured using the ETDRS letters. The rods are more vulnerable than the cones in both AMD and DR. These subtle changes in visual function may not be observed as a change in ETDRS letters as the test evaluates black letters on a white background from a distance. The FACT that we used in this study is considered to be more informative and accurate in assessing our day-to-day vision and has been used in previous studies evaluating the MP supplementation. ${ }^{19}$ Contrast sensitivity is a better predictor of the quality of visual function in macular diseases compared to visual acuity. Liu et $\mathrm{al}^{25}$ also noted a similar improvement in contrast sensitivity at middle and low frequencies.

The standard visual acuity testing using the ETDRS letters did not change at 3 months but showed a significant improvement at 6 months. Weigert et $\mathrm{al}^{31}$ suggested a similar delayed response of visual function in a well-powered randomized controlled trial on lutein supplementation in patients with ARM. In a meta-analysis of studies that evaluated the effect of lutein and zeaxanthin on visual function in patients with AMD, Liu et $\mathrm{al}^{25}$ showed that visual acuity gains may be noted only after 6 months compared to the more rapid response of increase in MPOD. The mean change of ETDRS score in our study was $1.5 \pm 4.6$ letters. The intersession variability of visual acuity ETDRS score is ten letters in early AMD and eleven letters in advanced AMD. ${ }^{32}$ Therefore, we should view these significant mean visual acuity results with caution. Weigert et $\mathrm{al}^{31}$ also evaluated the visual function as change in ETDRS letters and noted a very similar change of $2.1 \pm 0.4$ letters after 6 months.

Contrast sensitivity using Pelli-Robson scores did not change significantly in this study. A change criterion of six or more letters in Pelli-Robson chart in early AMD is recommended as a treatment effect in clinical trials. ${ }^{32,33}$ Two previous randomized controlled trials on oral carotenoid supplementation in ARM that used Pelli-Robson to evaluate contrast sensitivity also did not show any statistically significant change. ${ }^{34,35}$

The improvements in specific visual functions were also reflected in an improvement in the vision-related quality of life in mental health and near and distant vision and the general health-related quality of life measured using EQ-5D. This is the first study that has shown an improvement in patient-related outcomes following oral supplementation. Previous studies that evaluated visual function in ARM have not shown any significant changes after carotenoid supplementation. ${ }^{35,36}$ This discrepancy may be explained by the fact that this study consisted of patients with other retinal diseases, such as diabetic maculopathy and CSR where the resolution of macular pathology due to the natural history of the disease may have confounded the results. Furthermore, given the serious ceiling effects in both NEI-VFQ-25 and EQ-5D, these significant changes should be interpreted with caution. Previous studies showed that EQ-5D would be more suitable for measuring the health of patients with more morbidity. ${ }^{37-39}$ A majority of the patients in this cohort had normal or very minimal pathology in the nonstudy eye and would have contributed to the serious ceiling effects and the overall visual function of the individuals. The study results also inform us that the questionnaires used in this study may have been inadequate for demonstrating the functional effects of the supplementation. The NEI-VFQ-25 has only three items on low-luminance tasks that are focused exclusively on night vision, glare, and driving. It may be more appropriate to use the low-luminance questionnaire to evaluate the patient-related outcome measure in future studies on supplementations that improve glare sensitivity and night vision. ${ }^{40}$ Our study also showed that compliance with oral supplementation is very good in patients with retinal diseases. A limitation of this study is that plasma lutein was not measured. As such, we cannot rule out that those patients who had little increase in MPOD showed low adherence to the study medication.

\section{Conclusion}

In conclusion, this study has demonstrated an increase in MPOD objectively following the 6 months of macular carotenoid supplementation using the DWAF. Patients had a significant improvement in glare disability and low-contrast sensitivity, and so these tests may be a better outcome measure than the standard visual function outcome measures, such as change in ETDRS letters and contrast sensitivity letter scores using the Pelli-Robson test. Given that most of the patients in this study had diabetes or AMD, our study results may have important implications in improving the commonly reported problem of glare disability in these populations. Therefore, the findings in this study warrant further investigation in larger well-powered studies with longer follow-up in each disease area explored in this study to better understand the impact of this oral supplementation on visual performance.

\section{Acknowledgments}

Investigator initiated grant from the Howard Foundation. Macushield was supplied by Macuvision Europe, which is 
now part of Alliance Pharma Plc. The research was supported by the National Institute for Health Research Biomedical Research Centre based at Moorfields Eye Hospital NHS Foundation Trust and University College London Institute of Ophthalmology. The views expressed are those of the authors and not necessarily those of the NHS, the National Institute for Health Research, or the Department of Health.

\section{Disclosure}

The authors report no conflicts of interest in this work.

\section{References}

1. Loughman J, Nolan JM, Howard AN, Connolly E, Meagher K, Beatty S. The impact of macular pigment augmentation on visual performance using different carotenoid formulations. Invest Ophthalmol Vis Sci. 2012; 53(12):7871-7880.

2. Subczynski WK, Wisniewska A, Widomska J. Location of macular xanthophylls in the most vulnerable regions of photoreceptor outersegment membranes. Arch Biochem Biophys. 2010;504(1):61-66.

3. Lien EL, Hammond BR. Nutritional influences on visual development and function. Prog Retin Eye Res. 2011;30(3):188-203.

4. Beatty S, Koh H, Phil M, Henson D, Boulton M. The role of oxidative stress in the pathogenesis of age-related macular degeneration. Surv Ophthalmol. 2000;45(2):115-134.

5. Kowluru RA, Kowluru A, Mishra M, Kumar B. Oxidative stress and epigenetic modifications in the pathogenesis of diabetic retinopathy. Prog Retin Eye Res. 2015;48:40-61.

6. Nolan JM, Beatty S, Meagher KA, Howarth PA, Kelly D, Thurnham DI. Verification of meso-zeaxanthin in Fish. J Food Process Technol. 2014; 5(6):335.

7. Maoka T, Arai A, Shimizu M, Matsuno T. The first isolation of enantiomeric and meso-zeaxanthin in nature. Comp Biochem Physiol B. 1986; 83(1):121-124.

8. Bone RA, Landrum JT, Fernandez L, Tarsis SL. Analysis of the macular pigment by HPLC: retinal distribution and age study. Invest Ophthalmol Vis Sci. 1988;29(6):843-849.

9. Johnson EJ, Neuringer M, Russell RM, Schalch W, Snodderly DM. Nutritional manipulation of primate retinas, III: effects of lutein or zeaxanthin supplementation on adipose tissue and retina of xanthophyllfree monkeys. Invest Ophthalmol Vis Sci. 2005;46(2):692-702.

10. Nolan JM, Meagher K, Kashani S, Beatty S. What is meso-zeaxanthin, and where does it come from? Eye (Lond). 2013;27(8):899-905.

11. Trieschmann M, Beatty S, Nolan JM, et al. Changes in macular pigment optical density and serum concentrations of its constituent carotenoids following supplemental lutein and zeaxanthin: the LUNA study. Exp Eye Res. 2007;84(4):718-728.

12. Mares JA, LaRowe TL, Snodderly DM, et al; CAREDS Macular Pigment Study Group and Investigators. Predictors of optical density of lutein and zeaxanthin in retinas of older women in the carotenoids in age-related eye disease study, an ancillary study of the women's health initiative. Am J Clin Nutr. 2006;84(5):1107-1122.

13. Howells O, Eperjesi F, Bartlett H. Measuring macular pigment optical density in vivo: a review of techniques. Graefes Arch Clin Exp Ophthalmol. 2011;249(3):315-347.

14. Bartlett H, Acton J, Eperjesi F. Clinical evaluation of the MacuScope macular pigment densitometer. Br J Ophthalmol. 2010;94(3):328-331.

15. Gallaher KT, Mura M, Todd WA, et al; Health ABC Study. Estimation of macular pigment optical density in the elderly: test-retest variability and effect of optical blur in pseudophakic subjects. Vision Res. 2007; 47(9):1253-1259.

16. Robson AG, Moreland JD, Pauleikhoff D, et al. Macular pigment density and distribution: comparison of fundus autofluorescence with minimum motion photometry. Vision Res. 2003;43(16):1765-1775.
17. Degli Esposti S, Egan C, Bunce C, Moreland JD, Bird AC, Robson AG. Macular pigment parameters in patients with macular telangiectasia (MacTel) and normal subjects: implications of a novel analysis. Invest Ophthalmol Vis Sci. 2012;53(10):6568-6575.

18. Bone RA, Landrum JT, Gibert JC. Macular pigment and the edge hypothesis of flicker photometry. Vision Res. 2004;44(26):3045-3051.

19. Hammond BR Jr, Fletcher LM, Elliott JG. Glare disability, photostress recovery, and chromatic contrast: relation to macular pigment and serum lutein and zeaxanthin. Invest Ophthalmol Vis Sci. 2013;54(1): 476-481.

20. Mangione CM, Lee PP, Gutierrez PR, et al; National Eye Institute Visual Function Questionnaire Field Test Investigators. Development of the 25-item National Eye Institute visual function questionnaire. Arch Ophthalmol. 2001;119(7):1050-1058.

21. Rabin R, De Charro F. EQ-5D: a measure of health status from the EuroQol group. Ann Med. 2001;33(5):337-343.

22. Nolan JM, Akkali MC, Loughman J, Howard AN, Beatty S. Macular carotenoid supplementation in subjects with atypical profiles of macular pigment. Exp Eye Res. 2012;101:9-15.

23. Canovas R, Lima VC, Garcia P, Morini C, Prata TS, Rosen RB. Comparison between macular pigment optical density measurements using two-wavelength autofluorescence and heterochromatic flicker photometry techniques. Invest Ophthalmol Vis Sci. 2010;51(6): 3152-3156.

24. Gong X, Rubin LP. Role of macular xanthophylls in prevention of common neovascular retinopathies: retinopathy of prematurity and diabetic retinopathy. Arch Biochem Biophys. 2015;572:40-48.

25. Liu R, Wang T, Zhang B, et al. Lutein and zeaxanthin supplementation and association with visual function in age-related macular degeneration. Invest Ophthalmol Vis Sci. 2014;56(1):252-258.

26. Sabour-Pickett S, Beatty S, Connolly E, et al. Supplementation with three different macular carotenoid formulations in patients with early age-related macular degeneration. Retina. 2014;34(9):1757-1766.

27. Sasamoto Y, Gomi F, Sawa M, Tsujikawa M, Nishida K. Effect of 1-year lutein supplementation on macular pigment optical density and visual function. Graefes Arch Clin Exp Ophthalmol. 2011;249(12): 1847-1854.

28. Zeimer M, Dietzel M, Hense HW, Heimes B, Austermann U, Pauleikhoff D. Profiles of macular pigment optical density and their changes following supplemental lutein and zeaxanthin: new results from the LUNA study. Invest Ophthalmol Vis Sci. 2012;53(8):4852-4859.

29. Li B, Vachali P, Bernstein PS. Human ocular carotenoid-binding proteins. Photochem Photobiol Sci. 2010;9:1418-1425.

30. Barker FM, Snodderly DM, Johnson EJ, et al. Nutritional manipulation of primate retinas, V: effects of lutein, zeaxanthin, and n-3 fatty acids on retinal sensitivity to blue-light-induced damage. Invest Ophthalmol Vis Sci. 2011;52:3934-3942.

31. Weigert G, Kaya S, Pemp B, et al. Effects of lutein supplementation on macular pigment optical density and visual acuity in patients with age-related macular degeneration. Invest Ophthalmol Vis Sci. 2011; 52(11):8174-8178.

32. Patel PJ, Chen FK, Rubin GS, Tufail A. Intersession repeatability of visual acuity scores in age-related macular degeneration. Invest Ophthalmol Vis Sci. 2008;49(10):4347-4352.

33. Patel PJ, Chen FK, Rubin GS, Tufail A. Intersession repeatability of contrast sensitivity scores in age-related macular degeneration. Invest Ophthalmol Vis Sci. 2009;50(6):2621-2625.

34. Bartlett HE, Eperjesi F. Effect of lutein and antioxidant dietary supplementation on contrast sensitivity in age-related macular disease: a randomised controlled trial. Eur J Clin Nutr. 2007;61:1121-1127.

35. Piermarocchi S, Saviano S, Parisi V, et al; Carmis Study Group. Carotenoids in Age-related Maculopathy Italian Study (CARMIS): two-year results of a randomized study. Eur J Ophthalmol. 2012;22:216-225.

36. Ma L, Yan SF, Huang YM, et al. Effect of lutein and zeaxanthin on macular pigment and visual function in patients with early age-related macular degeneration. Ophthalmology. 2012;119:2290-2297. 
37. Pesudovs K, Gothwal VK, Wright T, Lamoureux EL. Remediating serious flaws in the National Eye Institute visual function questionnaire. $J$ Cataract Refract Surg. 2010;36(5):718-732.

38. Bharmal M, Thomas J 3rd. Comparing the EQ-5D and the SF-6D descriptive systems to assess their ceiling effects in the US general population. Value Health. 2006;9(4):262-271.

39. Wu J, Han Y, Zhao FL, Zhou J, Chen Z, Sun H. Validation and comparison of EuroQoL-5 dimension (EQ-5D) and Short Form-6 dimension (SF-6D) among stable angina patients. Health Qual Life Outcomes. 2014; 12(1): 156
40. Owsley C, McGwin G Jr, Scilley K, Kallies K. Development of a questionnaire to assess vision problems under low luminance in age-related maculopathy. Invest Ophthalmol Vis Sci. 2006;47(2): 528-535.

41. Mangione CM, Lee PP, Gutierrez PR, Spritzer K, Berry S, Hays RD; National Eye Institute Visual Function Questionnaire Field Test Investigators. Development of the 25-item National Eye Institute Visual Function Questionnaire. Arch Ophthalmol. 2001;119(7):1050-1058.
Clinical Ophthalmology

\section{Publish your work in this journal}

Clinical Ophthalmology is an international, peer-reviewed journal covering all subspecialties within ophthalmology. Key topics include: Optometry; Visual science; Pharmacology and drug therapy in eye diseases; Basic Sciences; Primary and Secondary eye care; Patient Safety and Quality of Care Improvements. This journal is indexed on

\section{Dovepress}

PubMed Central and CAS, and is the official journal of The Society of Clinical Ophthalmology (SCO). The manuscript management system is completely online and includes a very quick and fair peer-review system, which is all easy to use. Visit http://www.dovepress.com/ testimonials.php to read real quotes from published authors. 